\title{
Chemoreduction of Orbital Recurrence of Uveal Melanoma by Intra-Arterial Melphalan
}

\author{
Jasmine H. Francis ${ }^{a, b}$ Christopher A. Barker ${ }^{c}$ Vivian T. Yin ${ }^{a, b}$ \\ Richard D. Carvajal $^{d}$ Paul Chapman ${ }^{b, e}$ David H. Abramson ${ }^{a, b}$ Y. Pierre Gobin ${ }^{b}$ \\ ${ }^{a}$ Ophthalmic Oncology Service, Memorial Sloan Kettering Cancer Center, New York, NY, USA; b Weill-Cornell \\ Medical Center, New York, NY, USA; ' Department of Radiation Oncology, Memorial Sloan Kettering Cancer \\ Center, New York, NY, USA; ${ }^{d}$ Department of Medicine, Columbia University Medical Center, New York, NY, USA; \\ e Department of Medicine, Memorial Sloan Kettering Cancer Center, New York, NY, USA
}

\section{Established Facts}

- Orbital recurrence of uveal melanoma may occur in approximately one-quarter of eyes with known extraocular extension on histopathology.

- The treatment of orbital recurrence of uveal melanoma is challenging: exenteration can be disfiguring and does not always control local disease.

\section{Novel Insights}

- Intra-arterial melphalan delivered to the orbit can cytoreduce (but not cure) orbital recurrence of uveal melanoma.

- Intra-arterial melphalan delivered to the orbit at doses as high as $30 \mathrm{mg}$ may result in temporary periocular erythema but appears to have limited permanent alterations in cosmesis.

\section{Keywords}

Intra-arterial chemotherapy · Neoplasia · Orbit · Orbital tumor - Uveal melanoma

\section{Abstract \\ Background/Aims: The treatment of orbital melanoma pos- es a management challenge. This case explores the delivery of high-dose melphalan to an orbital recurrence of uveal melanoma via intra-arterial delivery of melphalan to the or-}

bit. A 62-year-old man developed recurrent orbital disease 7 months after enucleation for a large uveal melanoma. He received 6 monthly intra-arterial infusions of melphalan to the orbit, ranging in dose from 20 to $30 \mathrm{mg}$ per infusion. Following the last infusion, mild temporary erythema was noted on the forehead along the distribution of the supratrochlear ar-

This case was presented, as part of a talk, at the Macula Society Meeting, Los Angeles, February 2018.

\section{KARGER}

(C) 2018 S. Karger AG, Basel

E-Mail karger@karger.com

www.karger.com/oop
Jasmine H. Francis, MD

Memorial Sloan Kettering Cancer Center

1275 York Ave.

New York, NY 10065 (USA)

E-Mail francij1@mskcc.org 
tery. The orbital recurrence was reduced in size by $66 \%$ in the longest dimension as measured by magnetic resonance imaging (MRI). However, 9 months following intra-arterial melphalan, tumor regrowth was detected on MRI, and additional treatment options were pursued. Conclusion: This case demonstrates that intra-arterial melphalan can result in nonsustained tumor regression of recurrent orbital uveal melanoma. It suggests that local delivery of high-dose melphalan may be helpful as a neoadjuvant treatment for uveal melanoma, and future studies will be useful to confirm the value of this approach in additional cases of recurrent and possibly in primary uveal melanoma.

(c) 2018 S. Karger AG, Basel

\section{Introduction}

Primary orbital melanoma is extremely rare [1]. However, orbital melanoma may develop, either from direct extension of an intraocular or surface tumor, or from metastatic disease recurring in this location. Up to $15 \%$ of enucleated uveal melanomas are found to have some degree of extraocular extension, which has been associated with increased tumor size and high-risk cytogenetic features [2,3]. The Collaborative Ocular Melanoma Study (COMS) found that external beam radiotherapy did not affect the rate of metastasis but did reduce the incidence of orbital recurrence [4].

Despite histopathological findings, orbital recurrence occurs in only $3-23 \%$ of eyes with known extraocular extension [3]. However, orbital recurrence poses a clinical challenge should it occur. Treatment options are disfiguring, and many tumors will progress despite management with surgery and radiation. This present case is a patient with orbital recurrence of uveal melanoma, who refused exenteration and desired exploration of alternate management options.

This case borrows from the cutaneous melanoma literature and involves localized, high-dose delivery of melphalan to the orbit. Isolated limb perfusion of melphalan was first described as a single case report by Creech et al. [5] in 1957 and is now a well-established technique for inoperable recurrent cutaneous melanoma affecting an extremity [6]. It consists of localized delivery of cytotoxic melphalan to the site of disease, without exposing vital organs to the consequences of these high doses. A similar technique, percutaneous isolated hepatic perfusion, involves a similar technique of melphalan delivery and has established a hepatic control rate for uveal melanoma of $82.4 \%$ [7-9]. Our group has extensive experience in ap- plying this rationale to the treatment of retinoblastoma through the technique of ophthalmic artery chemosurgery [10]. Therefore, we used a similar technique to deliver intra-arterial melphalan to the orbit of a single case with recurrent orbital uveal melanoma; and this report describes the response and outcome.

\section{Case Report}

A 62-year-old man weighing $97 \mathrm{~kg}$ with melanosis oculi was enucleated for a COMS large ciliochoroidal melanoma [11]. Seven months later, he reported a change in his prosthesis fitting, and magnetic resonance imaging (MRI) revealed a large orbital mass, confirmed as recurrent uveal melanoma on biopsy (Fig. 1). Both the primary and orbital tumors had gene expression profile class IA and disomy 3 [12]. The orbital tumor demonstrated somatic mutations in GNAQ and SF3B1 and an absence of BAP1 mutation [13]. Imaging revealed no evidence of regional or distant metastases. The accepted treatment options were discussed with the patient (including proton beam radiation and exenteration). He adamantly refused exenteration. An additional meeting was set up in the presence of the patient's family to review the option of exenteration, and still the patient refused. A fully informed consent was obtained outlining the known and potential unknown risks, benefits, and alternatives, and the patient decided to undergo monthly intra-arterial melphalan to the orbital tumor. The initial infusion delivered $3 \mathrm{mg}$ to the anterior deep temporal artery (ADTA) and $7 \mathrm{mg}$ via the ophthalmic artery (OA). A second (4 mg via ADTA and $11 \mathrm{mg}$ via OA) and third ( $3 \mathrm{mg}$ via ADTA and $12 \mathrm{mg}$ via $\mathrm{OA}$ ) infusion were given. The fourth infusion delivered $3 \mathrm{mg}$ to the anterior branch of the superficial temporal artery, $5 \mathrm{mg}$ via ADTA and $12 \mathrm{mg}$ via OA. A repeat MRI demonstrated a measurable contraction of the tumor, but with residual tumor in the inferior lateral orbit. For this reason, the infraorbital artery (IOA) was accessed for the final 2 infusions: the fifth infusion delivered $10 \mathrm{mg}$ via IOA, $8 \mathrm{mg}$ via ADTA, and 12 $\mathrm{mg}$ via $\mathrm{OA}$. The sixth infusion delivered $7 \mathrm{mg}$ via IOA, $8 \mathrm{mg}$ via ADTA, and $15 \mathrm{mg}$ via OA. Following this, the orbital uveal melanoma demonstrated a dramatic reduction in size with minimal radiographic evidence of residual tumor: specifically, $1.1 \times 1.3 \mathrm{~mm}$ to $0.6 \times 0.8 \mathrm{~mm}$ (Fig. 1). After the final infusion, the patient reported temporary erythema on his forehead skin along the distribution of the supratrochlear artery, which resolved within 2 weeks and without any permanent sequelae. There was no evidence of hematologic toxicity during the treatment course as measured by complete blood count. The blood count nadir is 7-10 days after chemotherapy: results during this time period revealed a hemoglobin range of $15.2-16.3 \mathrm{~g} / \mathrm{dL}$, a platelet count range of $144-218 \times 10^{3} / \mu \mathrm{L}$, and absolute neutrophil count of $3.2-4.2 \times 10^{3} / \mu \mathrm{L}$. These results are within the normal range.

Nine months following treatment, a repeat MRI demonstrated recurrent disease in the orbit, and the patient received proton beam radiotherapy. Seven months following radiation, recurrence was again noted, and the patient enrolled in 2 experimental trials of systemic therapy (including immunotherapy). Stability was initially noted, but disease again recurred, and the patient eventually agreed to exenteration. He remains free of metastasis at 48 months of follow-up from orbital recurrence. 

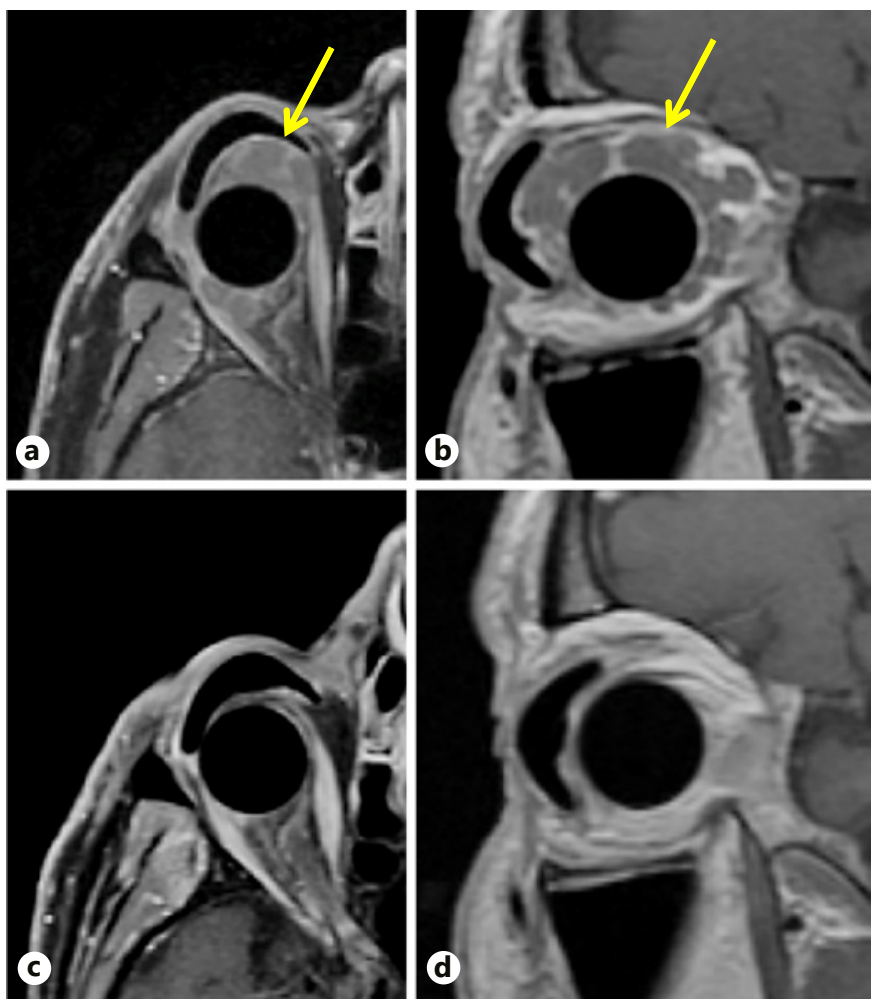

Fig. 1. a T1-weighted fat-saturated magnetic resonance (MR) axial image of the right orbit demonstrating biopsy-proven uveal melanoma surrounding the orbital implant. Arrow demonstrates tumor. b T1-weighted fat-saturated MR sagittal image of the right orbit demonstrating biopsy-proven uveal melanoma circumscribing the orbital implant. Arrow demonstrates tumor. c T1-weighted fat-saturated MR axial image of the right orbit following 6 infusions of ophthalmic artery chemosurgery (OAC) demonstrating contraction of orbital melanoma. d T1-weighted fat-saturated MR sagittal image of the right orbit following 6 infusions of OAC demonstrating contraction of orbital melanoma.

\section{Discussion}

The treatment options for orbital melanoma are limited to either radiation or surgical excision, typically by exenteration [14-19], as no chemotherapy, biologic or targeted therapy has been proven to prolong survival. Both options can be disfiguring and are not always effective at preventing progression of disease [15]. Likewise, in this case, the intra-arterial melphalan was not curative of disease, and the tumor recurred at 9 months of follow-up.

The drug choice of melphalan is grounded in clinical responses noted in the treatment of cutaneous melanoma by isolated limb perfusion and liver metastases of uveal melanoma by isolated hepatic perfusion $[5,6,9]$. Preclinical data support the therapeutic response of human melanoma lines to melphalan and have shown an enhanced response with hyperthermia [20, 21]. However, these studies focus on cutaneous melanoma cell lines, and few have focused on uveal melanoma cell lines. One may question whether other intra-arterial drugs may be useful in this disease. Unfortunately, there is little evidence to suggest that uveal melanoma would respond to the other 2 agents (carboplatin and topotecan), which are routinely delivered via ophthalmic artery chemosurgery. However, there is a possibility that carboplatin, as a platinum-based agent, may radiosensitize uveal melanoma to subsequent radiation [22].

In contrast to the closed circulation of isolated limb perfusion and percutaneous isolated hepatic perfusion involving arterial infusion and venous extraction of the drug, intra-arterial chemotherapy consists solely of drug infusion. This may raise concern for an increased risk of myelosuppression in the latter technique. However, "most" patients treated with isolated limb perfusion received granulocyte colony-stimulating factor [9]. On the contrary, our single patient did not have evidence of myelosuppression. This may be partly attributable to drug dose: in isolated hepatic perfusion, patients receive $3 \mathrm{mg} / \mathrm{kg}$ per treatment, and our patient was given between 0.10 and $0.39 \mathrm{mg} / \mathrm{kg}$ per infusion.

However, the importance of this case lies in the demonstration that intra-arterial melphalan delivered via ophthalmic artery chemosurgery can dramatically reduce uveal melanoma (by $66 \%$ on radiographic imaging) and is well tolerated. For this patient, it effectively resulted in tumor regression with limited transient skin erythema, no systemic toxicity, and with little alteration in cosmesis. Despite being only a single case, it lays the precedent for other possible indications for intra-arterial melphalan in the treatment of ocular melanoma. For instance, intra-arterial melphalan could be used as an adjunct to chemo-reduce orbital uveal melanoma prior to surgical excision or radiation. Or it could be used to reduce large uveal melanomas to a size that could appropriately receive definitive treatment with plaque brachytherapy. In support of this, it is known from the retinoblastoma literature that intra-arterial melphalan results in a substantial dose of drug to the choroid [23]. Or perhaps it could be used in the management of other ocular melanomas, such as refractory conjunctival melanomas with orbital extension. Despite the distinct genetics of conjunctival melanomas (which aligns more with that of cutaneous melanoma), the favorable results of intra-ar- 
terial melphalan in cutaneous melanoma suggest that it may be useful in its conjunctival counterpart.

We encourage larger studies to validate these findings and further refine the utility of intra-arterial melphalan in the treatment of ocular melanoma.

\section{Statement of Ethics}

The patient provided written informed consent for all treatments, including the use of imaging. This single case study did not require review/approval by the Memorial Sloan Kettering Institutional Review Board.

\section{Disclosure Statement}

The relevant financial and commercial conflicts are as follows: Richard Carvajal: AstraZeneca, BMS, Castle Biosciences, Foundation Medicine, Immunocore, Incyte Merck Novartis, Roche/Genetech, Aura Biosciences, Chimeron Rgenix. Paul Chapman: Merck, Cell Medica, Astra Zenica, Takeda, Pfizer, Genentech. Christopher Barker: Bristol Myers Squibb, Merck, Amgen, Pfizer, Novartis. None of the other authors have any financial disclosures or conflicts.

\section{Funding Sources}

This study was supported in part by the Fund for Ophthalmic Knowledge and Perry's Promise Fund and Cancer Center Support Grant (P30 CA008748).

\section{References}

1 Figueira E, Rajak S, McKelvie P, Kalantzis G, Ismail A, Gonzales $\mathrm{M}$, et al: Primary orbital melanoma: a case series and literature review. Orbit 2018;27:1-6.

2 Coupland SE, Campbell I, Damato B: Routes of extraocular extension of uveal melanoma: risk factors and influence on survival probability. Ophthalmology 2008;115:1778-1785.

3 Van Beek JGM, Koopmans AE, Vaarwater J, de Rooi JJ, Paridaens D, Naus NC, et al: The prognostic value of extraocular extension in relation to monosomy 3 and gain of chromosome 8q in uveal melanoma. Invest Ophthalmol Vis Sci 2014;55:1284-1291.

4 Hawkins BS; Collaborative Ocular Melanoma Study Group: The Collaborative Ocular Melanoma Study (COMS) randomized trial of preenucleation radiation of large choroidal melanoma: IV. Ten-year mortality findings and prognostic factors. COMS report number 24 . Am J Ophthalmol 2004;138:936-951.

5 Creech O, Krementz ET, Ryan RF, Winblad $\mathrm{JN}$ : Chemotherapy of cancer: regional perfusion utilizing an extracorporeal circuit. Ann Surg 1958;148:616-632.

6 Nieweg OE, Kroon BBR: Isolated limb perfusion with melphalan for melanoma. J Surg Oncol 2014;109:332-337.

7 Alexander HR, Libutti SK, Bartlett DL, Puhlmann M, Fraker DL, Bachenheimer LC: A phase I-II study of isolated hepatic perfusion using melphalan with or without tumor necrosis factor for patients with ocular melanoma metastatic to liver. Clin Cancer Res 2000; 6:3062-3070.

8 Alexander HR, Libutti SK, Pingpank JF, Steinberg SM, Bartlett DL, Helsabeck C, et al: Hyperthermic isolated hepatic perfusion using melphalan for patients with ocular melanoma metastatic to liver. Clin Cancer Res 2003;9:6343-6349.
9 Karydis I, Gangi A, Wheater MJ, Choi J, Wilson I, Thomas K, et al: Percutaneous hepatic perfusion with melphalan in uveal melanoma: a safe and effective treatment modality in an orphan disease. J Surg Oncol 2017;98:383.

10 Gobin YP, Dunkel IJ, Marr BP, Brodie SE, Abramson DH: Intra-arterial chemotherapy for the management of retinoblastoma: fouryear experience. Arch Ophthalmol 2011;129: 732-737.

11 Margo CE: The Collaborative Ocular Melanoma Study: an overview. Cancer Control 2004;11:304-309.

12 Onken MD, Worley LA, Ehlers JP, Harbour JW: Gene expression profiling in uveal melanoma reveals two molecular classes and predicts metastatic death. Cancer Res 2004;64: 7205-7209.

13 Cheng DT, Mitchell TN, Zehir A, Shah RH, Benayed R, Syed A, et al: Memorial Sloan Kettering-Integrated Mutation Profiling of Actionable Cancer Targets (MSK-IMPACT): a hybridization capture-based next-generation sequencing clinical assay for solid tumor molecular oncology. J Mol Diagn 2015;17:251264.

14 Saadati H, Calvano C, Diba R, Fuller GN, Gombos D, De Monte F, et al: Orbital and optic chiasmal extension of uveal melanoma. Ophthalmic Plast Reconstr Surg 2004;20: 387-390.

15 Ross JJ, Dean SJ, Koppel DA, Roberts F, Kemp EG: Massive orbital recurrence of uveal melanoma without metastases after 28 years. $\mathrm{Br}$ Ophthalmol 2010;94:632.
16 Finger PT, Tena LB, Semenova E, Aridgides P, Choi WH: Extrascleral extension of choroidal melanoma: post-enucleation high-doserate interstitial brachytherapy of the orbit. Brachytherapy 2014;13:275-280.

17 Coupland SE, Sidiki S, Clark BJ, McClaren K, Kyle P, Lee WR: Metastatic choroidal melanoma to the contralateral orbit 40 years after enucleation. Arch Ophthalmol 1996;114: 751-756.

18 Abramson DH, Servodidio CA: Metastatic choroidal melanoma to the contralateral orbit 40 years after enucleation. Arch Ophthalmol 1997;115:134.

19 Shields JA, Perez N, Shields CL, Singh AD, Eagle RC: Orbital melanoma metastatic from contralateral choroid: management by complete surgical resection. Ophthalmic Surg Lasers 2002;33:416-420.

20 Goss P, Parsons PG: The effect of hyperthermia and melphalan on survival of human fibroblast strains and melanoma cell lines. Cancer Res 1977;37:152-156.

21 Parsons PG, Morrison L: Melphalan-induced chromosome damage in sensitive and resistant human melanoma cell lines. Int J Cancer 1978;21:438-443.

22 Koukourakis MI, Stefanaki I, Giatromanolaki A, Frangiadaki C, Armenaki A, Georgoulias V, et al: Fractionated carboplatin radiosensitization: a phase I dose-escalation study. Am J Clin Oncol 1998;21:595-601.

23 Schaiquevich P, Buitrago E, Taich P, Torbidoni A, Ceciliano A, Fandino A, et al: Pharmacokinetic analysis of melphalan after superselective ophthalmic artery infusion in preclinical models and retinoblastoma patients. Invest Ophthalmol Vis Sci 2012;53:4205-4212. 